\title{
Mental health services on Lower North Shore, Sydney
}

\author{
Mike Slade
}

This paper describes mental health services in the Lower North Shore (LNS) catchment area of Sydney, Australia, and is based on a visit made in early 1994. The local population of 170,000 is predominantly caucasian, but there are also groups from other ethnic backgrounds. The mental health service has about 800 registered clients, with 60 new clients each month, the majority of whom have a serious mental illness. Since the service has won several awards, it may be instructive to review its structure and function.

\section{Overview of LNS paychiatric services}

Services are based around two community mental health centres, each of which has a permanent multidisciplinary staff of about ten, together with trainees from various professions. The continuity of care provided by case managers is integrated with a 24 hour crisis response service ('extended hours team'). Non-medical team members (occupational therapists, psychiatric nurses, psychologists, social workers) are rostered on duty until 10.30 p.m., with two members on call overnight. Separate 24 hour medical cover is provided by a combination of hospital and community medical staff. Since 1988 a separate mobile intensive case management team of 6.5 staff has worked with serlously mentally ill clients who had not benefited from previously existing services, especially those with unstable accommodation or dual diagnosis of substance abuse. Fifteen inpatient beds are provided at a locked general hospital ward, with a few back-up beds avallable for longer-term or more secure admissions at the Gladesville/Macquarie combined psychiatric hospitals, one campus of which is in the process of closure.

Rehabilitation services are offered by the rehabilitation resource team, where four staff work with 120 clients to faclitate their achieving optimal functioning and becoming active community members. Other rehabilitation options are a vocational training programme, a work co-operattve (paying a real wage and with supported employment placements in the private sector), and eight residential sites with 43 beds in total are available. Each site offers a different level of support, ranging from a permanently staffed home for 13 residents to a 16-bedded core and satellite home network of five houses with visiting staff. The key principles informing service development are service-user rights, normalisation, rapid crisis response, continuity of service, case management, multidisciplinary teams, integration of services and quality management (Kral \& Flannery, 1992).

\section{Principles of care}

The principle that the service should be usercentred is central to service planning in LNS. Integration of mental health services into the community is important, so many service faclities are based in houses. Normalisation is used as a philosophy to guide interventions. Services are designed to be in the least restrictive environment, and to promote dignity and enhance self-respect. Implementing these principles is helped by the New South Wales Mental Health Act (1990) which makes provision for community counselling orders (CCOs), giving staff legal rights of access to a community client for treatment and rehabilitation, and community treatment orders (CTOs), for community continuation of involuntary treatment commenced in hospital. Neither order allows medication to be enforced in the community, for which a return visit to hospital for assessment is necessary. My impression was that these orders are used sparingly, and seen by staff as a last resort. Often merely the imposition of a CTO led to improved cooperation with medication and rehabilitation, without any need to enforce 
the Order-the stamp of officialdom was sufficient. Given the current debate about community supervision orders in the UK, the experience in Sydney would suggest that such legislation may not be abused if it exdists in the context of a user-orlented mental health service.

\section{Billingual counsellors}

Within the LNS catchment area, the main ethnic groups are Armenian, Iranian and Afghani. Fifteen per cent of registered users do not come from Anglo-Saxon backgrounds, and $4 \%$ are not fluent in English. Part-time bilingual counsellors are employed for these clients. They are also avallable to assist other teams in performing assessments. This is reciprocated by bilingual workers in other teams, so that a trained counsellor is available for most languages. This contrasts with the use in Britain of bilingual staff who need not have any mental health training.

\section{Case management}

All mental health professionals carry a generic case-load, 1.e. they are not assigned clients on the basis of their professional training. If a social worker (for example) thinks that a client would benefit from psychological therapy, he or she will carry it out directly under the supervision of a clinical psychologist. All case managers are expected to undertake mental state examinations, and the legal responsibility for care rests both with the care manager and the psychiatrist directly involved in treatment or supervision of the client. The non-medical members of a mental health team are either employed by professional discipline or as mental health workers, a role with no equivalent in the UK. Use of multidisciplinary mental health workers is appropriate where there are many shared core duties, and result in highly mottvated teams, where the work is often both diverse and rewarding for each cliniclan. Furthermore, the integration of professional development and practice meant that clinical work by all professions is grounded in research, perhaps not always the case in Britain.

\section{Dependency rating}

Teams use dependency ratings to measure the burden of each term member's caseload. This allows team leaders to ensure that the stressful aspects of the work are shared equally through the team, and provides a rationale for deciding on the provision of extra staff. Several approaches are being piloted. One assessment uses the number in the caseload, frequency of contact, risk (e.g. suicidal, chronic psychosis, violence), hospital factors (e.g. admission to hospital, CTO, acute psychosis), functional disability (e.g. self-care, self responsibility, lack of social contacts), involvement of the staff member with the family, and liaison with other professionals. A more comprehenstve dependency rating looks at all the factors associated with each client that requires the professional to do more work. Experience in using this assessment suggests that it improves staff morale, since team members realise how much they are doing for their clients. In the climate of economic evaluation of services which is prevalent in the UK dependency rating tools might be appropriately introduced into routine clinical practice, since they give a rational model for assessing and distributing case load levels.

\section{Financing health care}

Medicare, a untversal national health insurance system, reimburses general practitioners and prtvate psychiatrists on an open ended fee for service basis, and provides free public hospital care. Most patients with mental disorders are treated by general practitioners, but there are also many prtvate psychiatrists, who see more patients than are seen by staff in the public sector Hke the Lower North Shore service. Private psychiatrists tend to avold the seriously mentally ill, who will not come to them or miss appointments, whereas public services prioritise this client group and their families. Recently, however, insurance companies have been raising premiums due to increased claims, resulting in fewer policles being taken out. Some managers felt that the rising cost of medical technology will inevitably lead to the phasing out of private health insurance.

\section{Frtended hours tenms}

One of the key practical issues for developing community care teams in Britain is the configuration of crisis teams. The extended hours team began as a separately staffed crisis team (Hoult et al, 1984), but over time was 
integrated with pre-existing community mental health teams. Separate crisis teams gave better short-term outcomes, because of the intenstve, dedicated support. It was also a helpful configuration when setting the service up, because both teams were mottvated to 'out-perform' the other. Longer term, however, It was found that better outcomes were assoclated with an integrated team, since episodes of illness were more rapidly detected by a staff member who is familiar with the person, and the continuity of service was helpful for clients in crisis-a client sees the same person (or a close colleague) at 3 a.m. as they would at midday. Furthermore, the reduced rivalry led to higher morale in the team.

\section{Mobile ascertive case management teams}

An important component of the LNS mental health services is the mobile community management team, which uses assertive outreach to engage clients who have a serious mental lliness and either repeated hospital admissions or who make intenstve use of existing community based services. Close liaison between the mobile and community teams ensures that referrals to the moblle team are appropriate, and transfer back to the community team is supported. Contact takes place in the client's home, and may involve help with practical matters, medication advice, advocacy, symptom monitoring and early intervention, or family education. The caseload never exceeds one staff member to ten clients. Evaluation is seen as a component of routine clinical work, and engagement with the mobile team has been assoclated with reduced hospital admissions and better community functioning (Hambridge \& Rosen, 1992). Both the integration of intervention with evaluation and the use of assertive outreach are already features of good practice in some Britlsh settings.

Learning from the experience of others is not a one-way process-the possibility of a purchaser/provider split is being discussed in Australia. However, many of the issues that have been addressed in LNS are relevant to mental health service development in Britain.

\section{Acknowiedgements}

I think the Harold Hyam Wingate Foundation for funding the visit, and all the staff in Lower North Shore Area for their helpfulness.

\section{References}

Humbridos, J. \& Rosin, A (1992) Assertue Communthy Treatment for the Serloushy Mentally III in Suburbar Sydney: an evaluation of a mobile communtty management team Sydney: Royal North Shore Hoepital and Community Health Services.

Hourt. J.. Rosen, A. \& Renvouds, I. (1984) Community orientated treatment compared to peychiatric hospital orientated treatment. Social Sclence and Medictre. 18. 1005-1010.

Kral, D. \& Finnverry, F. (1992) Mental Health Servtces Information Document. Sydney: Royal North Shore Hospital and Community Health Services.

Mike Slade, Research Psychologist, PRISM (Psychiatric Research in Service Measurement), Institute of Psychiatry, De Crespigny Park, Denmark HIIl, London SE5 \&AF 